\title{
El turista cultural y las ciudades históricas
}

Maribel Rodríguez Achútegui

Espiral SL, Dinamización del Patrimonio

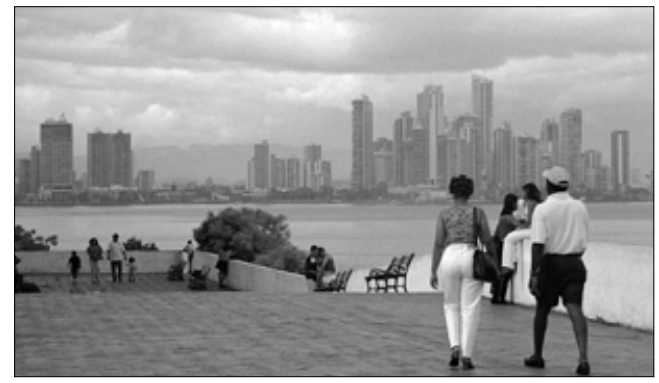

"Las ciudades, como los sueños, están construidos de deseos y temores, aunque el hilo de su discurrir, sea secreto, sus normas absurdas, sus perspectivas engañosas, y cada cosa esconda otra."

Italo Calvino. Las Ciudades Invisibles

\section{Resumen}

El turismo cultural es un fenómeno reciente que surge como consecuencia del alto nivel de vida que se ha conseguido en las sociedades desarrolladas, es decir es el resultado final de un proceso de mejoras sociales, incremento del tiempo libre y diversificación de las actividades de ocio. Fruto de esta demanda, la oferta turística ha evolucionado hacia productos culturales de calidad. Sin embargo aún son escasos los estudios que se llevan a cabo sobre el protagonista de este fenómeno, un público que se desconoce, que es cada vez más exigente, al que hay que prever y educar para que no arrastre a su paso la verdadera identidad de las ciudades. Una oportunidad que hay que planificar y gestionar para conseguir una experiencia social, y cultural, que sea rentable económicamente. Una experiencia integradora.

\section{Palabras clave}

Turismo cultural / Ciudad / Estudio de público / Segmentación de público / Mercado

En las últimas décadas se está tomando conciencia de la importancia que el turismo cultural tiene para las ciudades históricas, importancia que se traduce tanto en términos monetarios como en otros aspectos más difíciles de contabilizar, como la imagen, el prestigio o el despertar de inquietudes culturales y sociales motivadas en parte por la presencia de los flujos turísticos. Pero lo más interesante de todo, es que esta toma de conciencia no se ha quedado circunscrita sólo a las grandes ciudades monumentales que ya son vinculadas tradicionalmente con el turismo, sino que por el contrario, se ha extendido a muchas otras en las que son especialmente importantes los valores no cuantificables de los que se ha hablado.

Ahora bien, si esta concienciación ha permitido que en muchas ciudades de interior se realicen esfuerzos para fomentar el turismo cultural, también es cierto que en algunos de los casos, hay una gran falta de planificación previa, que se traduce en fenómenos como la inexistencia de gestión adecuada de los recursos, la estandarización que surge de intentar copiar formulas exitosas de otros lugares, o la inadecuación de los servicios a las necesidades y gustos del turista de hoy.

Es importante detenerse de forma especial en este último punto, puesto que quien realmente va a decidir el éxito de cualquier iniciativa en turismo cultural es su público, y su valoración estará condicionada no sólo por criterios estéticos (la belleza de lo visitado) sino por muchos otros aspectos como el grado en que ha sido capaz de despertar interés aquello que se ha visto, su capacidad de comunicación, de cubrir expectativas, etc. $Y$ pese a que este es un hecho claro ¿conocemos a nuestros visitantes?, y si no es así ¿dedicamos el esfuerzo necesario a conocerlos? Re- 
El hombre contemporáneo ha hecho del consumo cultural una práctica generalizada dentro de sus hábitos de ocio y tiempo libre. Con esta práctica busca no sólo encontrar explicación a los fenómenos en sí mismos, sino que pretende encontrarse a sí mismo, definirse como persona buscando referentes culturales propios o a través del contacto con otras realidades distintas

almente es siempre muy interesante realizar un estudio de público que nos permita adecuar los esfuerzos en la planificación de servicios a las demandas reales de nuestros visitantes, aunque lo cierto es que en muchos casos la realidad presupuestaria no permite un estudio en profundidad.

No obstante sí que se puede reflexionar sobre una serie de aspectos básicos para llegar a acercarnos de la forma más efectiva a nuestro público.

\section{¿Quién es el turista cultural?}

En los últimos tiempos los cambios sociales y culturales de nuestra sociedad, han creado un tipo de turista que tiene unas motivaciones diferentes. Así frente al turismo de sol y playa, denominamos turista cultural a aquél que tiene una serie de motivaciones patrimoniales y culturales que le mueven a escoger un lugar para conocerlo. Es decir, que busca conocer en su visita el patrimonio histórico y natural de la ciudad: trama urbana, murallas, calles, plazas, palacios, iglesias, museos, etc., así como otras manifestaciones como son: paisajes, fiestas, gastronomía, folklore,... u otras representaciones culturales contemporáneas: conciertos, exposiciones de arte, etc.

Este fenómeno ha ocurrido en paralelo a la modificación, no sólo cuantitativa sino también cualitativa, de la propia consideración de patrimonio y cultura. De ser una definición ligada en principio a las grandes manifestaciones del Arte y de la Historia, se ha pasado a una generalización casi absoluta de la consideración de patrimonio y cultura. Así, en la actualidad, forman parte de la cultura el paisaje, las formas de vida y particularidades de las comunidades, la gastronomía, el recuerdo de personajes o momentos determinados, las tradiciones... y un largo etcétera que coincidirá en extensión con la capacidad de adaptación de las comunidades a su entorno territorial.

El hombre contemporáneo ha hecho del consumo cultural una práctica generalizada dentro de sus há-

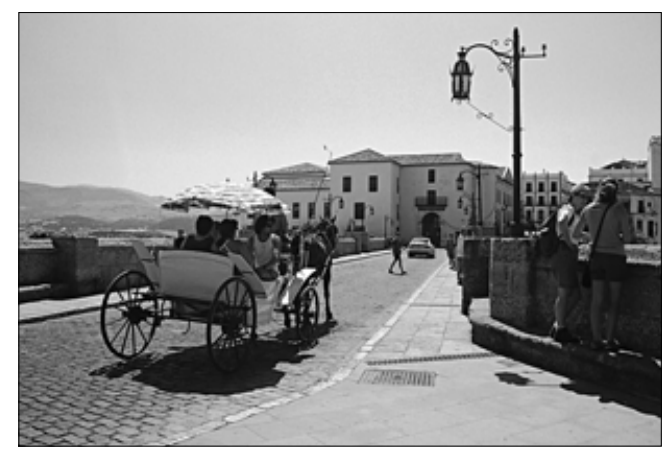

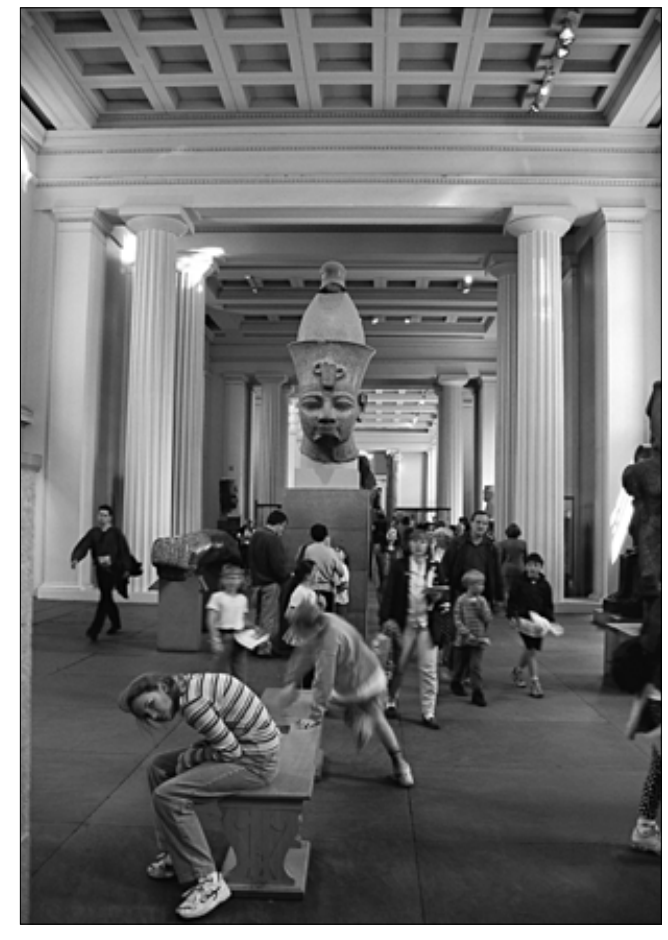

bitos de ocio y tiempo libre. Con esta práctica busca no sólo encontrar explicación a los fenómenos en sí mismos, sino que pretende encontrarse a sí mismo, definirse como persona buscando referentes culturales propios o a través del contacto con otras realidades distintas $!$.
I. Ronda ¿Ciudades para vivir o ciudades para visitar?

2. Londres. ¿Quién es el turista cultural?

I. V.V.A.A. Sueños e identidades. Una aportación al debate sobre Cultura y Desarrollo en Europa. Consejo de Europa e Interarts, Barcelona 1999. 
Es por ello que la práctica del turismo cultural tendrá un componente heterogéneo que conjuga aspectos tan diversos como el ocio, la diversión, la formación, etc., e incluso otros que tienen que ver con el posicionamiento social, la moda...

Es fundamental que tengamos claro que el turismo se desarrolla dentro del marco del tiempo libre del público y que por lo tanto se inserta (con una relación tanto de complementariedad como de competencia) dentro de la industria del ocio.

Por tanto para que una ciudad, o cualquier territorio diseñe y trabaje en un producto que cumpla las expectativas de este tipo de turismo, que en general suele buscar la calidad y es exigente, es necesario tener en cuenta sus intereses y necesidades

\section{¿Cuáles son las necesidades básicas de un turista cultural?}

Lo expuesto es un marco mental y social en el que se integra en la actualidad el fenómeno del turismo cultural, pero además hay que tener en cuenta, que un viajero es ante todo una persona y tiene una serie de necesidades básicas, que es necesario cubrir para que su viaje sea satisfactorio. Según Maslow ${ }^{2}$ hay una serie de categorías en las necesidades del hombre, se encuentre donde se encuentre, $y$ a todas ellas hay que buscar, en la medida de lo posible, dar respuesta satisfactoria:

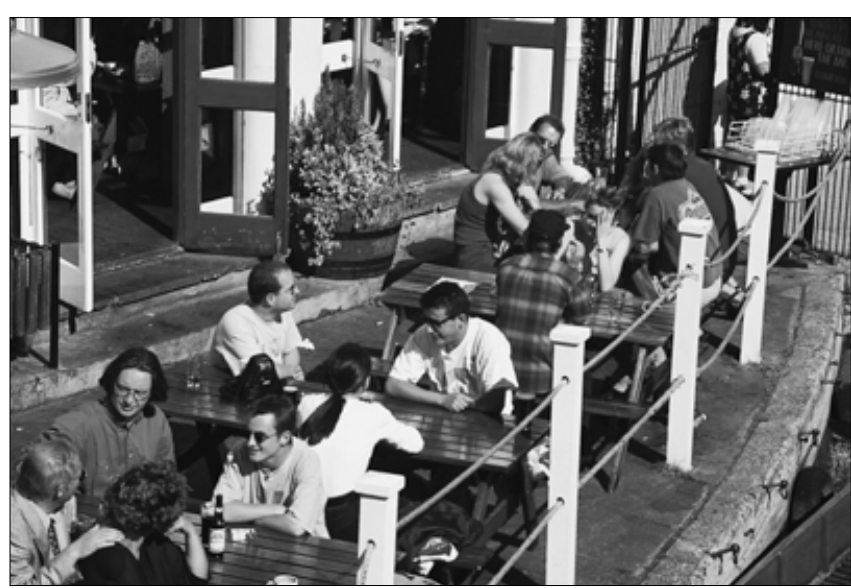

3. Cambridge ¿Cuáles son las necesidades básicas del turista cultural?

Necesidades Fisiológicas:

\section{De seguridad:}

Es necesario que dotemos a nuestro espacio turístico de los instrumentos necesarios para que el visitante se pueda mover con tranquilidad en él, así aspectos como una correcta señalización orientadora, el establecimiento de áreas de aparcamientos a las que acceder sin dificultad, una correcta información que le permita conocer la globalidad de la oferta, así como la posibilidad de seleccionar y diseñar su visita, son algunos de los factores que permiten que un visitante se sienta seguro en un espacio turístico. ción de las Ciudades y Villas de Arte e Historia. Francia. Personality.New York: Harper \& Row
MASLOW, Abraham (1954).

\section{De pertenencia y amor}

Aunque de una forma más abstracta, también podemos orientar nuestro trabajo hacia esta necesidad. En un mundo globalizado un individuo busca los vestigios de su identidad y espera distinguirse en ese mundo sin rostros, por lo que anhela vivir experiencias que le permitan creer que son únicas, que han sido diseñadas para él o para el colectivo con el que se identifica. El objetivo, por tanto, es conseguir que el turista se sienta partícipe de lo que visita y para ello a lo largo del entramado de servicios con el que presentemos la ciudad (folletos, guías, audioguías, exposiciones, actividades de animación) es importante dirigirnos al público en primera persona, utilizar recursos como las preguntas, dispositivos interactivos, invitar directamente..., en resumen convertirlo en el protagonista de una historia que con su participación se convierte en propia.

\section{De autoestima}

En este aspecto hay que alejarse de la imagen y el trato que hemos heredado del turismo de masas de los años 60 y 70, y trabajar como un elemento importante la formación dirigida a aquellos que tienen contacto directo con el público. Hay ejemplos de programas de formación integral que contemplan no sólo a guías, monitores o personal de atención al visitante, sino también al personal de establecimientos hoteleros, de restauración e incluso policía local y taxistas ${ }^{3}$.

\section{De actualización}

Por lo que es importante mantener unos servicios dinámicos que combinen sistemas clásicos con nuevas tecnologías. La actualización no sólo de contenidos sino de formas. Sólo hay que observar a nuestro alrededor para ver las formas que adopta el lenguaje de la comunicación. Éstas deben ser las herramientas que necesitamos utilizar para participar en un mundo actual, para conseguir un diálogo fluido con el presente.

\section{De conocimiento y comprensión}

Es una de las necesidades en que tenemos que hacer un especial esfuerzo, ya que el conocimiento y la comprensión llevarán a una mayor valoración de nuestra ciudad por el visitante. En ese sentido cada vez más se tiende a intentar crear un espacio interpretativo en el que el público pueda captar una imagen global de la ciudad que le permita componer mejor las miles de imágenes que después encontrará en ella.

\section{Estéticas}

Lo que implica tener un especial cuidado con el diseño de todos los soportes informativos e interpretativos con los que se comunique con el visitante.

Entre ellas, unas más y otras menos, pero todas se pueden tener en cuenta a la hora de diseñar un producto de turismo cultural. 


\section{¿Cuáles son sus intereses?}

Para empezar podemos decir, que entre los intereses fundamentales que motivan al turista cultural ( $y$ hablamos de intereses o de gustos, a satisfacer), hay tres tipos fundamentales:

- Histórico-nostálgico: Se trata del gusto, un tanto romántico, de lo antiguo. Pueden disfrutar con ruinas, solamente por sus valores estéticos y simbólicos. No necesitan prácticamente ningún tipo de explicación o comunicación para salir satisfechos.

- Mecánico-moderno: En este caso se trata del disfrute que se alcanza a través del conocimiento de los mecanismos que rodean al patrimonio. Son aquellos turistas que para salir satisfechos de una visita deben conocer el quién, cómo, cuándo y fundamentalmente los porqué de las cosas. Están por tanto especialmente interesados en los procesos que llevan a que algo sea tal y como lo ve. Serán por tanto los que disfruten comprendiendo y viendo el funcionamiento de un molino, o los distintos sistemas de ataque y defensa de un castillo.

- Eco-deportista: Se trata del interés y motivación especial hacia el medioambiente, paisajes, formas de vidas tradicionales, etc., lo que se une con el gusto por deportes de bajo impacto. Son aquellos que disfrutan haciendo senderismo, alpinismo, etc. Aunque parezcan los más alejados de tema de las ciudades, hoy por hoy, también se deben y pueden tener en cuenta. Un ejemplo claro es el camino de Santiago en el que se reúnen los valores culturales de las ciudades o pueblos y los naturales y deportivos del camino.

\section{Análisis de mercado}

Además de estas cuestiones generales, cuando estemos analizando un destino turístico cultural necesitaremos identificar diferentes segmentos o sectores de mercado entre los visitantes y los residentes. Cualquier propuesta de interpretación no se puede acomodar de la misma manera a los distintos tipos de visitantes. Por ello es necesario identificar las características de cada grupo.

En términos generales, un análisis de mercado debe incluir:

- detección de la demanda recreativa y turística a nivel local, regional, nacional o internacional y sus previsiones futuras;

- estudio de las predicciones de la población local;

- identificación de otras atracciones de ocio y turismo que compitan con las nuestras;

- selección de información sobre el uso por el público de las ofertas de ocio y recreación existentes en la zona;

- examen de la imagen actual de promoción del área;

- revisión de los problemas de gestión de visitantes (si los hubiere);

- análisis de los segmentos de mercado.

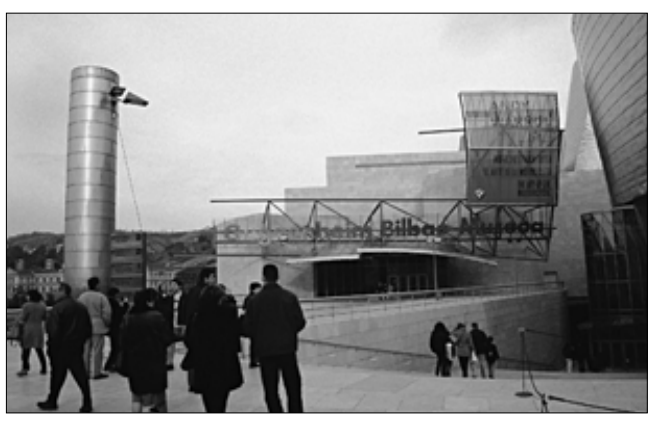

La palabra mercado, aunque posee connotaciones negativas, por cuanto puede ser entendida como una mercantilización de la cultura, no es más que una expresión economicista de una metodología de trabajo, utilizada normalmente en turismo. Nosotros entendemos "el mercado" como el marco en el que se producen intercambios de valores culturales, sociales y también económicos. Los compradores o los usuarios en este caso son los visitantes. Las características de estos visitantes, sus aspiraciones, deseos, orígenes, educación, etc., van a condicionar las reglas de este intercambio. Por tanto, merece la pena hacerse las siguientes preguntas a cerca de los visitantes potenciales:

- quiénes son;

- cómo podemos contactar con ellos y que método de promoción podemos usar;

- qué mensaje debe ser transmitido;

- cómo debemos abordar la promoción:

- qué servicios se demandan.

Para conocer mejor a nuestro público empezaremos por plantearnos:

- edad,

- nivel de estudios,

- lugar de procedencia,

- motivaciones

- hábitos culturales,

- expectativas de la visita,

Y para los grupos tendremos que tener en cuenta las siguiente variables:

- Propósito del grupo: educación, ocio, curiosidad... - Número de individuos que componen el grupo.

- Tipo: familiar, escolar, de congreso, en turoperador...

- Composición: homogéneo, heterogéneo

\section{¿Cómo podemos obtener esa información?}

Hay dos posibilidades claras, o bien a través de datos primarios (investigación específica del mercado por observación, encuestas, cuestionarios, etc. ) o bien a través de fuentes secundarias (otros estudios, estadísticas o informes anteriores).

A partir de esto tenemos que ir definiendo diferentes segmentos de mercado, es decir agrupar los individuos, potenciales consumidores, que conforman los mercados, en grupos homogéneos y específicos (heterogéneos entre si) mediante criterios adecuados a las características y motivaciones de cada mercado.
4. Bilbao ¿Históricos, nostálgicos, mecánicos, modernos...? 
Para una segmentación, lo principal que hemos de tener en cuenta son las ventajas o beneficios básicos, buscados por el consumidor en la contratación de los servicios, para así identificar los factores claves de éxito de cada segmento de mercado.

Las divisiones pueden ser muy variables, según la necesidad de los proyectos, por ejemplo, en general la audiencia se puede clasificar y segmentar en:

- turing o turistas culturales en ruta,

- visitantes provinciales y regionales,

- turistas extranjeros

- grupos organizados,

- turistas de convenciones,

- residentes locales,

- grupos escolares,

- grupos o individuos especialmente interesados,

- etc...

Por cada uno de esos grupos es necesario establecer:

- porqué visitan la ciudad, el lugar histórico o la comarca,

- cuánto tiempo pretenden permanecer en el área,

- qué nivel de interés pueden tener en el lugar,

- que te gustaría que ellos hicieran durante su visita al lugar.

\section{Matriz de posicionamiento}

Una vez detectados nuestros públicos potenciales, sus características y de dónde vienen, realizaremos una matriz de posicionamiento, o matriz de atractivo - competitividad.

\section{Atractivo}

En cuanto al atractivo, lo que sopesaremos es:

- Dimensión: Número de personas.

- Crecimiento: Tendencia del mercado. Aquellos mercados con crecimiento más elevado serán los más atractivos.

- Nivel de Competencia: Posibles destinos que pueden cubrir, a priori, sus necesidades. Cuantas más opciones tengan para escoger, menos atractivo va a tener un mercado (hay mayor competencia).

- Nivel de Gasto: Será más atractivo aquel mercado que tenga el gasto medio más elevado, en función de la duración de su estancia.

- Accesibilidad: la facilidad (en términos de inversión, datos y conocimiento del mercado, etc.) de acceder a un mercado, lo hace más atractivo.

\section{Competitividad}

La Posición Competitiva respecto a cada uno de los mercados se valorará mediante las siguientes variables: Cuota de mercado: Hace referencia a la proporción de mercado que actualmente se capta. Cuanto más grande sea la cuota, mejor será la posición competitiva.

Calidad del Producto: Mide la calidad del producto turístico básico para cada mercado. La posición competitiva mejorará cuando los productos sean de mejor calidad.

Imagen: La imagen turística del territorio para cada mercado. Cuanto más conocido sea el territorio como destino turístico, mejor posición competitiva tendrá.

Calidad de los recursos: Esta variable introduce una vertiente de futuro, ya que valora la capacidad de los actuales recursos turísticos para constituir un producto turístico.

La matriz Atractivo/Posicionamiento Competitiva permite una jerarquización de los mercados a partir de la valoración de ambas variables. Así pues, presenta diferentes zonas:

- Mercados a priorizar: Se trata de mercados de gran atractivo y en los que le territorio tiene una posición competitiva privilegiada.

- Mercados a potenciar: Son aquellos mercados con un grado de atractivo alto o medio y una posición competitiva buena o media. En estos casos se puede potenciar su desarrollo para que pasen a ser prioritarios.

- Mercados a mantener y gestionar: Es trata de mercados con un grado de atractivo medio, en los que se tiene una buena posición competitiva. Son mercados que difícilmente pasaran a ser prioritarios, pero en los que se puede seguir trabajando y mejorar la gestión para mantenerlos.

- Mercados a aprovechar: Se trata de aquellos mercados en los cuales, a pesar de tener un grado de atractivo medio-alto, la posición competitiva es baja. Por tanto podemos aprovecharlos, sin dedicarles demasiados recursos, para mejorar su posición competitiva.

- Mercados a controlar: Son aquellos mercados poco atractivos en los cuales se Tiene una buena posición competitiva. En estos casos hay que controlar, para tratar de mantenerlos sin que suponga una fuerte inversión.

\section{Priorización de mercados}

Los mercados se clasificarán seleccionado en dos grupos, en base a los siguientes criterios:

- Ubicación en la matriz Atractivo/ Posicionamiento Competitivo: Tal y como se ha expuesto en el apartado anterior, la ubicación de los diferentes mercados en la matriz, muestra la relación entre su atractivo y la posición competitiva. Ambas variables son decisivas a la hora de priorizar los mercados. 
- Grado de consecución de los objetivos establecidos: La situación actual de la comarca y su planteamiento de futuro son dos aspectos que se han de tener en cuenta a la hora de priorizar mercados objetivos. Por tanto, serán más prioritarios aquellos mercados que favorezcan la consecución de los objetivos.

- Factibilidad: La capacidad para dirigirse a un mercado determinado (en términos de personas implicadas, coordinación, inversión, rentabilidad,...) es el tercer elemento a tener en cuenta.

\section{Finalmente, ¿para qué un análisis de mercado?}

Hemos comprobado que el turismo cultural es un fenómeno reciente que inunda ahora nuestras ciudades patrimoniales, que esta llegando al territorio como una mancha de aceite que se expande poco a poco, esperada y ansiada a la vez por las expectativas que ha creado: creación de empleo, rentabilidad económica y social del patrimonio, ayudas a la restauración y conservación del patrimonio para su comprensión y visita, creación de centros de interpretación...

Hemos descubierto, que si bien estas expectativas han llegado hasta los últimos rincones de nuestra geografía, no han llegado siempre de la mejor forma posible, acompañadas de una adecuada planificación y gestión ${ }^{4}$, así como de un esfuerzo por conocer al visitante que va a protagonizar la demanda en este sector.

Creemos que es necesario conocer a este público

- Porque sólo conociéndolo, podremos descubrir qué es lo que espera de nuestras ciudades y sus habitantes y modelar una oferta de calidad para los visitantes y los residentes, una oferta real y vi-

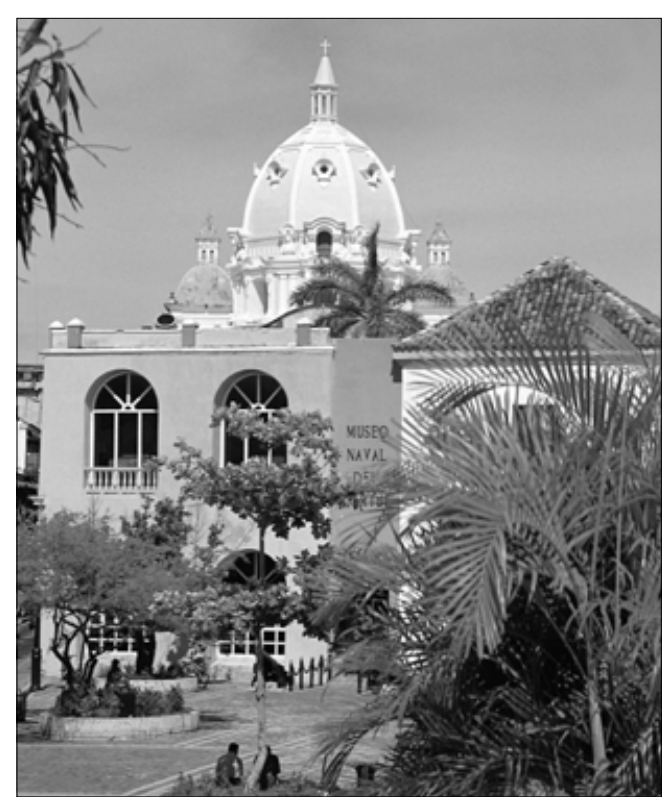

5. Cartagena de Indias. Ciudades escaparate, recuperadas para el turismo

va, que no sea sólo un escaparate para el turismo, sino una forma de vida.

- Porque sólo conociéndolo podremos educarlo en el respeto a otras culturas, a otras ciudades, contenedores de una herencia viva que se plasma en sus calles, en sus edificios, en sus habitantes.

- Porque sólo así podremos integrar a los visitantes entre nuestras calles e intentar evitar la visión del turista cultural como un mero depredador de nuestro patrimonio ciudadano, al que hay que explotar,

Porque sólo así veremos el lado humano del turismo cultural, un fenómeno, que esperamos posea un fuerte componente social o cultural.
4. "Para conseguir que esta industria que puede ser portadora de esperanza y educación, no traiga consigo problemas que afecten a la conservación de las colecciones, la destrucción de sitios arqueológicos o vaya en detrimento de la interpretación del patrimonio. $E$ turismo cultural tiene que estar en manos de profesionales del patrimonio" Jacques Perot, $19^{\mathrm{a}}$ Conferencia General del ICOM. Barcelona 2001.

\section{Bibliografía}

GRÖTSCH, K (2000). Economía de Sensaciones o la Gestión de las Emociones. Congreso Internacional de Ocio, Deusto.

PLAN Senda: desarrollo de un sistema turístico sostenible y competitivo integrado en el espacio rural andaluz (2000). Consejería de Turismo y Deporte, Sevilla.

V.V.A.A. Legado arquitectónico y turismo rural. Actas de las I Jornadas de Patrimonio de la Alpujarra.

V.V.A.A. (1999). Indicadores para la evaluación del estado de conservación de Ciudades Históricas. Instituto Andaluz del Patrimonio Histórico. Serie Cuadernos, Sevilla.

Turismo y patrimonio monumental (1999). Red Andaluza de Servicios Avanzados a las Empresas (Red CSEA). Confederación de Empresarios de Andalucía, Sevilla.

KEATING, F (1999). Trapping tourists. Museums-Journal, v. 99, n5, p43.

MÁLAGA solar del paraíso: pasado, presente y futuro del patrimonio arquitectónico de Málaga (1999). ADEPMA, Málaga.

TROITIÑO, M.A. (1998) Turismo y desarrollo sostenible en las ciudades históricas. En Ería, revista cuatrimestral de geografía $n^{\circ} 47$.
Número monográfico dedicado al turismo en las ciudades históricas. Departamento de Geografía de la Facultad de Geografía e Historia, Universidad de Oviedo

Actas del Congreso Europeo sobre Itinerarios Culturales y Rutas Temáticas, Logroño 1997. (1998). Fundación Caja Rioja. Logroño 1998

ROMERO MORAGAS, C. La ciudad histórica y las estrategias de comunicación. En "Turismo, conservación y rehabilitación del patrimonio arquitectónico y artístico" Cáceres, 16-18 de octubre de 1997.

MIRÓ, M. (1997). Interpretación, Identidad y Territorio. Una reflexión sobre el uso social del patrimonio. En "Boletín del Instituto Andaluz del Patrimonio Histórico", Sevilla: Consejería de Cultura de la Junta de Andalucía, núm. 18.

GONZÁLEZ MÉNDEZ, M. (1996). Turismo alternativo y patrimonio cultural: una relación ambigua. Revista de arqueología $n^{\circ} 17$ (186), pp.6-7.

RICHARDS, G. (edited by) (1995) European Tourism and Leisure Education: Trends and Prospects. Tilburg: Tilburg University Press.

The Training of Cultural Animators amd Administrators, Joint Study, $n^{\circ} 10$, UNESCO 